\title{
Automotive Digital Earth: Big Data, Insurance
}

\author{
Nikita Nosov ${ }^{* 1}$ \\ ${ }^{1}$ Lomonosov Moscow State University, Moscow, Russia, nosov_nikita@mail.ru
}

\begin{abstract}
The article is devoted to the implementation of Big Data technology in the auto industry and insurance. The article substantiates the need to use this technology in the context of rapidly growing volumes of information, describes the role of big data in modern life and predicts its use in the concept of the future development of the Digital Earth. The current level of Big Data usage in the automotive sector in Russia and around the world is considered. The author describes the main areas of application of Big Data, such as car insurance using telematics devices, navigation, improving the production process of cars in terms of identifying and eliminating system flaws that are detected during operation, as well as about the growing popularity and at the same time causing heated controversy of the technology of unmanned driving. Statistical data on the number of self-driving cars in countries, the level of their introduction into everyday life, and people's readiness for a new stage of transport development are presented. Separately, the author raises the question of the legal regulation of Big Data, which at this stage is in its infancy and requires careful study, identifies current legal problems that arise in the process of implementing this technology. As a solution to the problem, a number of measures are proposed to fill the existing gap and establish compliance with the rule of law and common principles for the use and protection of Big data.
\end{abstract}

Keywords

Big Data, Digital Earth, Self-driving cars.

\section{Introduction}

One of the branches of Digital Earth society is the information service technology, as well as possibilities for future development of human life on earth in general. The amount of information in all areas of our life is constantly growing, so we have to develop advanced technologies such as the Internet of things, artificial intelligence, blockchain and Big Data, which create an opportunity to move to an absolutely new level of life on Earth.

The Digital Earth concept implies a future with a free access to knowledge, any scientific or cultural information, which will enable the entire mankind to better understand our planet itself and how it is affected by human activity.

There is a rapid development in the area of the so-called "Big Data" which directly contributes to our everyday life. It allows people to deal with large volumes of information in various fields, for example, geomorphology, meteorology, developing "smart cities" infrastructure, medicine, building construction, transport and many others. Today I would like to talk about how Big Data can be applied in the automotive industry. In the modern world the amount of information is increasing rapidly that's why we need ways to store, process and analyze data, as well as to manage all these processes.

\footnotetext{
Corresponding author
} 


\section{Discussion}

An example of a promising area, involving Big Data, is the automotive field, which includes various branches:

1. Insurance. Realization of the "Pay-as-you-drive" concept (or PAYD). Telematics is successfully utilized by insurance companies, allowing to substantially decrease the cost of a car insurance certificate. It also simplifies and speeds up the resolution of arguable issues in case of an accident by collecting such data as speed limits, the number of maneuvers, brakings and so forth.

2. Navigation. Cars with a telematics box become a part of the net and form a data current, by sending their coordinates every several seconds. The algorithm forms an efficient way to avoid traffic jams or road works.

3. Information for manufacturers. Big Data is actively used by automobile manufacturers: this includes information about a car's condition or about any possible trouble that a user can face during exploitation which helps to expose defects or reasons behind failures. Sellers also exploit such information with planning the purchase of spare parts or possible repair works.

4. Self-driving cars. As this area is attracting more and more attention, the amount of generated data is increasing as well. Here the main source of information is sensors and navigation system. Later on this will include information about the interaction with other road users and infrastructure components.

In accordance with the SAE J 3016-2018 standard "Classification and systematization, as well as definitions of terms related to driving automation systems for road motor vehicles", there are six levels of vehicle automation (Novotest.ru, 2018):

- Level 0 (no driving automation)

- Level 1 (driver assistance)

- Level 2 (partial driving automation)

- Level 3 (conditional driving automation)

- Level 4 (highly automated driving)

- Level 5 (full driving automation)

The second and third levels involve the use of systems such as cruise control, distance and lane control, and emergency braking. At present most vehicles belong to levels three/four, however some manufacturers offer a realization at the fifth stage (which is the case with Mercedes-Benz, for example). The Table 1 demonstrates a list of self-driving cars as well as their manufacturing 
countries. Their geographical spread is quite wide (Mentamore.com, 2019).

Table 1. Self-driving cars and their manufacturers

\begin{tabular}{l|c}
\multicolumn{1}{c|}{ Vehicle model } & Manufacturer, country \\
\hline GM Cruise & General Motors, USA \\
\hline Daimler Intelligent Drive & Mercedes, Germany \\
\hline Argo AI & Ford Motors Company, USA \\
\hline Honda & Honda Motor (Japan) and SenseTime (China) \\
\hline Yandex & Yandex, Russia \\
\hline Traffic Jam Pilot & Volkswagen and Audi, Germany \\
\hline
\end{tabular}

KPMG, a consulting company, regularly examines countries' readiness to use self-driving cars. The key factors are: security, data privacy, digital infrastructure, implications for the transport system, optimization of international travel and transportation.

Russia's position in this rating has remained low for several years (KPMG, 2020):

- 2018 year - 18-th place out of 20 ;

- 2019 year - 22-th place out of 25;

- 2020 year - 26-th place out of 30 .

The following criteria were taken into account:

- laws and governmental policy with regard to self-driving cars;

- the level of consumer acceptance;

- technology and innovation accessibility;

- the extent of the infrastructure required.

In November 2019 the Gartner company estimated the number of self-driving cars which came into existence in 2018 and 2019. 2018 showed 137129 new automated vehicles, whereas in 2019 this number elevated to 332932 (Gartner, 2019).

According to analysts' data, this number will still be increasing and by 2023 will have reached 745705 items (Table 2). The main growth is expected in North America, China and Western Europe and these regions are supposed to introduce unmanned driving rules.

The analysis was performed over all vehicles with autonomous driving equipment, meeting the requirements of automation level 3, which are capable of driving without human involvement. 
Table 2. Number of self-driving cars in the world

\begin{tabular}{l|c|c|c|c|c|c} 
Use Case & 2018 & 2019 & 2020 & 2021 & 2022 & 2023 \\
\hline Commercial & 2407 & 7250 & 10590 & 16958 & 26099 & 37361 \\
\hline Consumer & 134722 & 325682 & 380072 & 491664 & 612486 & 708344 \\
\hline Total & 137129 & 332932 & 390662 & 508622 & 638585 & 745705 \\
\hline
\end{tabular}

An opinion poll was taken by the IPSOS company (Kommersant.ru, 2018), and as a result it turned out that the interest to self-driving cars prevails all over the world (Fig. 1). Notably, neither North America nor Germany show any particular interest to autonomous vehicles, and that contradicts Gartner analysts' data expecting the number of self-driving cars to rise following the national policy in these countries. However, on average the situation seems to be quite positive throughout the world: $30 \%$ of participants are ready to drive such a car, while only $13 \%$ will reject this opportunity.

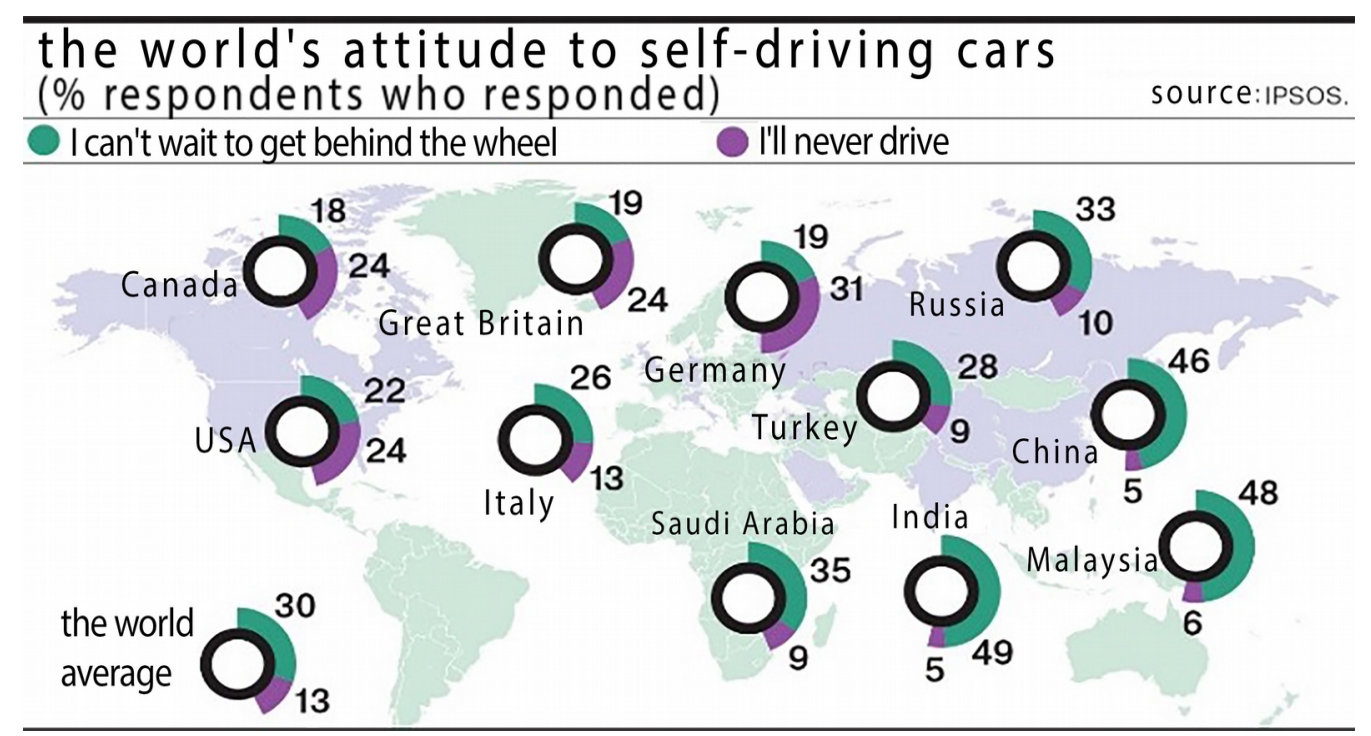

Fig. 1. The results of a survey by IPSOS (Kommersant.ru, 2018)

Regarding the Big Data issue in Russia, it is noteworthy that on the 9th of May in 2017 President signed the Strategy for the development of the information community in the Russian Federation in the period from 2017 to 2030 (Kremlin.ru, 2017). One of the main areas of development, concerning information and communication technologies, is specified as Big Data processing.

Nonetheless, at present in Russia there is no distinct definition for the term "Big Data" despite continuous attempts to introduce one. Several definitions, as well as terminology on the whole, 
were proposed in draft laws:

- in 2018 by the members of the State Duma (Gov.ru, 2018);

- in 2020 by the Ministry of communications (Gov.ru, 2020).

None of the proposed projects was accepted.

Along with the obvious advantages and development opportunities that Big Data might bring, unfortunately, we should also take into consideration the other side of the coin. Due to the novelty of this technology, there are no procedures for regulating data exploitation and processing. This requires:

- building a comprehensive terminology system;

- defining and demarcating responsibilities among all the participants involved in Big Data handling;

- developing algorithms and systems for Big Data protection and storage.

\section{Conclusions}

The use of Big Data technology naturally fits into the Digital Earth concept.

Given the high numbers of drivers throughout the Globe, Big Data management, introduced to the autonomous vehicles sector, is of top relevance to the Digital Earth project.

All in all, the legislative regulation of Big Data is missing, that is why in all ranking lists evaluating a country readiness for self-driving cars, Russia takes the lowest positions.

To sum up, given the international interest to Big Data, I would like to emphasize the necessity to modify our laws and regulations considering the Big Data issues. Besides, it is important to consistently regulate the areas, concerning Big Data and its protection.

\section{References}

Home.kpmg (2020) Countries' readiness to use self-driving cars URL: https://assets.kpmg/content/dam/kpmg/ru/pdf/2020/08/ru-ru-autonomous-vehicles-readiness-index2020.pdf Accessed 30 Dec 2020

Kremlin.ru (2017) Decree of the President of the Russian Federation No. 203. URL: http://www.kremlin.ru/acts/bank/41919 Accessed 30 Dec 2020

Gov.ru (2018) Draft law on amendments to the Federal law "About information, information 
technologies and information protection». URL: https://sozd.duma.gov.ru/bill/571124-7 Accessed 30 Dec 2020

Gov.ru (2020) Draft law on amendments to the Federal law «About information, information technologies and information protection». URL: https://regulation.gov.ru/p/99549 Accessed 30 Dec 2020

Gartner.com (2019) Gartner Forecasts More Than 740,000 Autonomous-Ready Vehicles to Be Added to Global Market in 2023. URL:

https://www.gartner.com/en/newsroom/press-releases/2019-11-14-gartner-forecasts-more-than740000-autonomous-ready-vehicles-to-be-added-to-global-market-in-2023 Accessed 30 Dec 2020

Kommersant.ru (2018) How to treat self-driving cars in the world. URL: https://www.kommersant.ru/doc/3597842 Accessed 30 Dec 2020

Mentamore.com (2019) Self-driving car market: realities and forecasts. URL: https://mentamore.com/transportnaya-infrastruktura/rynok-bespilotnyx-avtomobilej.html Accessed 30 Dec 2020

Novotest.ru (2018) The updated SAE J 3016 standard will bring the era of self-driving cars closer. URL: https://www.novotest.ru/news/world/obnovlennyy-standart-sae-j-3016-priblizitepokhu-bespilotnykh-avtomobiley/ Accessed 30 Dec 2020 